\title{
Browsing Lunar Surface Using Tabletop Augmented Reality at Exhibit in Science Museum
}

\author{
Kikuo Asai***, Tomotsugu Kondo****, Hideaki Kobayashi*** and Yuji Y. Sugimoto****
}

(Received 5 June 2011 and accepted in revised form 12 January 2012)

\begin{abstract}
We have developed a lunar surface browsing system with a tangible user interface by using augmented reality technology. It creates an interactive tabletop environment where learners can intuitively learn about lunar surface exploration from a printed map and multimedia projections. We performed two experiments to investigate the properties of the lunar surface browsing system. The first compared it with the moon as presented on Google Earth as a window, icon, mouse, and pointer (WIMP) environment. The results revealed that the lunar surface browsing system would be suitable as an interactive environment to assist children's learning. The second experiment was done in a practical situation at an exhibit in the Chiba Museum of Science and Industry. The results suggested that the browsing system would provide a learning environment where children and their parents could initiatively learn together.
\end{abstract}

Keywords: science museum, tabletop interface, visualization, lunar surface, augmented reality, user study

\section{Introduction}

Exhibits at museums have usually been organized based on real objects that have both educated and enlightened their visitors. Replicas have often been used if the real objects have not been able to be exhibited or have not been ideally suited for display. However, visitors only spend a short time on these exhibits ${ }^{(1,2)}$, because only simple explanations are provided for them and visitors want to see many others during their stay. Such glance-overs are insufficient to obtain knowledge that will become established in their memories.

Multimedia presentations and computer graphics are widely used for visualizing various types of data from digital archives ${ }^{(3,4)}$, so that visitors can expand their knowledge. Unfortunately, multimedia presentations often encourage visitors to behave passively resulting in children having difficulty in maintaining attention and cultivating learning initiatives.

Interactivity is an important factor in constructing knowledge and concepts for visitors and in motivating them to learn in museums ${ }^{(5-7)}$. Interactive experience provides children with an environment where they can

\footnotetext{
* The Open University of Japan

** The Graduate University for Advanced Studies, Japan

*** Waseda University, Japan

**** Doshisha University, Japan
}

enjoy learning. However, experiential exhibits such as playgrounds have often become just lighthearted environments for children to play in, not leading them to deeper comprehension of the phenomena that they experience. This presents a dilemma in that exhibits should be fun, but they also need to provide visitors with something to learn.

There have been attempts to make learning compatible with enjoyment by creating learning environments that improve visitors' interactions with exhibits and facilitate communication among visitors. An adaptive user interface supporting the context of play has been designed to balance the effectiveness and functionality of learning with playful interaction ${ }^{(8)}$. Designing interactions to be more physically accessible to children and parents has allowed collaborative learning to be emphasized through mutual conversations and discussions $^{(9)}$.

Our group has taken a map-based augmented reality (AR) approach to providing such an alternative learning environment ${ }^{(10)}$. Map-based AR enables geographic information to be overlaid on an actual map, allowing users to visualize the data linked to a location and its spatial features. An AR environment creates a tangible user interface that intuitively supports interactions with virtual objects by enabling the users to manipulate physical objects corresponding to data elements ${ }^{(11,12)}$. It also provides users with a collaborative environment by allowing them to share a common physical space, which 
enables communication behaviors to become easier, more natural, and social ${ }^{(13)}$.

Although some AR artifacts have been assembled for hybrid museum experiences that support visitors manipulating physical and digital materials ${ }^{(14-16)}$, few tabletop environments using map-based AR have been installed at museum exhibits or empirically investigated in detail within the context of making learning compatible with enjoyment. Therefore, more empirical studies need to be carried out before questions about the pedagogical value of tabletop AR environments can be answered and a map-based AR interface can be effectively used for learning in museum exhibits.

In a previous experiment, we conducted a user study under laboratory conditions by comparing a tabletop AR environment with a window, icon, mouse, and pointer (WIMP) environment ${ }^{17,}{ }^{18)}$. The originally designed system, GeoMovie Creator $(\mathrm{GMC})^{(19)}$ was used as a WIMP environment in that experiment. In this paper, the purpose of our preliminary experiment is to investigate the features of the tabletop AR environment compared to the WIMP environment in terms of not only efficiency but also suitability as an interface to science museums. Therefore, the moon in Google Earth was used in the preliminary experiment, since it was considered more general as an application on the WIMP environment. Then, we prepared a practical exhibit to investigate the potential of map-based AR as a learning environment and its usability as a geographic information viewer. The above framework of the experiments was taken because of the difficulty in obtaining permission to carry out rigidly controlled experiments in an actual science museum.

The moon is often used for learning content at science museums because it is the Earth's only satellite and the most familiar object in the sky after the sun. We have thus developed a lunar-surface browsing system using map-based AR. It creates a tabletop AR environment where users can interactively browse geographically embedded information about the exploration activities of the NASA Apollo missions ${ }^{(20)}$ and view realistic landscapes of the lunar surface from an egocentric viewpoint.

Here, we provide a description of the design concept underlying the lunar surface browsing system and a user study pairing the preliminary experiment with a practical exhibit. First, we describe work related to our map-based AR system and the user study followed by a discussion on the conceptual framework, i.e., its playful role in museums and its constructivist approach in learning. Second, we present an overview of the design and implementation of the lunar surface browsing system, in which visualization techniques were used to allow the tabletop AR environment to become more stable and interactive. Third, we describe the user study, in which we carried out the preliminary experiment comparing the tabletop AR environment with a WIMP environment and an exhibit displayed at the Chiba Museum of Science and Industry. We present the results we obtained from our evaluation and discuss lessons learned from the user study. Finally, we conclude with the finding that learning can be made compatible with playful interaction on a tabletop AR interface.

\section{Related Work}

Museum guides represent one of the most promising applications in AR. Current AR museum guides $^{(21-23)}$ mainly assist visitors with artwork appreciation and guidance. The former provides them with knowledge such as detailed descriptions of paintings, affinities with other paintings, and relationships within the artistic and social context to enable them to comprehend artworks. The latter guides visitors around exhibition spaces in the appropriate order. AR museum guide systems usually augment artifacts with text, video, and graphics involving spatial registration derived from visual tracking. Artifacts can be augmented with immersive computer graphics with see-through head-mounted displays (HMDs). For example, dinosaurs have been regenerated with animation overlaid onto real fossil skeletons ${ }^{(24)}$.

Wireless communications technologies such as RFID and wireless LAN have previously been used for detecting visitors' locations in mobile museum guides instead of AR. Mobile museum guides are capable of delivering personalized services based on visitor attributes such as preferences, age, and learning abilities ${ }^{(25,26)}$ and of offering advantages such as acquiring the behavior of visitors and supporting them in pre- and post-visit phases $^{(27,28)}$. In addition to supporting individual visitors, mobile museum guides have supported group communication at locations and provided context awareness to enable visitors to share museum experiences and encourage them to collaborate ${ }^{(29-31)}$. Many researchers have suggested that it is important to support group 
communication in museums ${ }^{(32,33)}$. General results from evaluation have been that although AR and mobile museum experiences have improved convenience for visitors, it has been difficult for them to turn their gaze from monitors to real exhibits, i.e., it has detached their interest from the actual museum exhibits.

Another concern is the claim that this means of communication isolates individual visitors from one another ${ }^{(34)}$. In fact, conversation is considered to be a key element to generally enhance learning and the quality of museum experiences ${ }^{(35)}$. Hybrid museum experiences have thus been designed giving priority to interaction with physical exhibition environments. The design and installation of the "Living Exhibition" have offered triggers to enhance curiosity and encourage collaborative behavior by direct manipulation of artifacts augmented with digital content ${ }^{(36)}$. Seamless integration of computer-generated visual information into artifacts is the same concept as that underlying AR.

AR technology has been applied to cartography to create a user interface that bridges the gap between computer-generated information and the everyday experiences of users ${ }^{(37)}$. Users of map-based AR can use a printed map to flexibly access geographic information by pointing at its location on the map and superimposing the information onto the map using a video seethrough $\mathrm{HMD}^{(38)}$ and a tabletop AR environment ${ }^{(39)}$. The Illuminating Clay system ${ }^{(40)}$, which is a geographic information system (GIS) interface for landscape design and analysis, uses a clay model instead of a printed map. Our browsing system is similar in concept to these mapbased visualization systems in that it provides a tangible user interface. However, the above systems have not targeted the use for education and they have not been evaluated as learning environments.

Many AR systems have been developed with some applications having targeted education. One AR system explaining the earth-sun relationship displays seasonal transitions in light and temperature by enabling the virtual sun and earth to be physically manipulated with handheld plates ${ }^{(41)}$. Construct3D, which is a 3D geometric construction tool for teaching mathematics and geometry, provides a basic set of functions for constructing primitive forms ${ }^{(42)}$. Augmented Chemistry is a virtual chemistry laboratory in which users view simple atoms and build complex molecules according to subatomic rules ${ }^{(43)}$. An AR-based system has recently been developed as a tangible learning environment for sup- porting spatial perception in learning the solar system $^{(44)}$. Even though a number of AR applications have been developed as demonstrations, there has not really been a consensus on the effectiveness of AR within educational contexts.

\section{Conceptual Framework}

Museums are considered to be unique environments that have different space and time to those experienced in daily life ${ }^{(45)}$, which is accomplished by mixing learning and leisure. Therefore, museums can be seen as having a 'cultural ecology' that has three components, liminality (experiences set apart from daily life), sociality (spaces enabling socialization between visitors), and engagement (interactions in learning and lighthearted ways) ${ }^{(46)}$. The three components are consistently embedded in a constructivist approach to learning, theoretically assuming that knowledge and concepts are created through experience and are obtained by interacting with information, tools, and materials as well as activities ${ }^{(47,48)}$.

We have considered that a tabletop AR environment produced by map-based AR has the potential to fulfill all these components. An AR environment enhances the real world by superimposing virtual objects onto a real scene. AR obscures the lines between the reality the learner is experiencing and the visual information being provided by the system ${ }^{(49)}$. The AR experience is considered to be like a magic trick that is not part of daily life.

Visitors often tend to visit museums in groups such as family and friends, and companions essentially affect individual behavior at museum exhibits ${ }^{(50)}$. Studies on parent-child interactions ${ }^{(51)}$ and those between grandparents and children ${ }^{(52)}$ have demonstrated that parents shape children's scientific thinking and grandparents act as interpreters and facilitators of children's experiences. A tabletop environment supports physically accessible interactions that enable parents and children to learn collaboratively through mutual conversations and discussions. We believe that an interactive tabletop environment using map-based AR can establish a foundation for both learning and enjoyment.

\section{System}

The lunar surface browsing system is a tabletop AR 


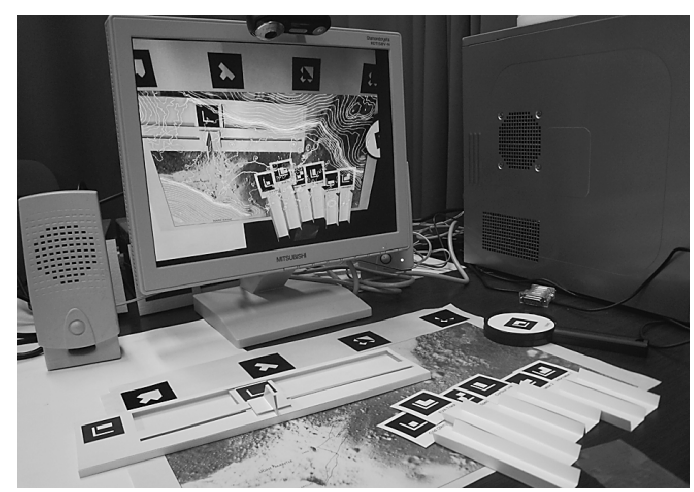

Figure 1. Overview of Lunar Surface Browsing System.

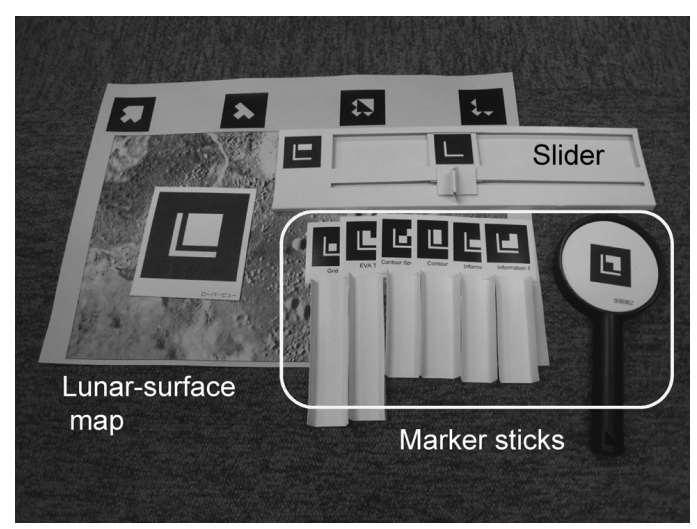

Figure 2. Lunar Surface Map (left) and Marker Sticks.

environment where users can browse geographic information using a printed map and marker sticks, as shown in Figure 1. They can learn about the exploration activities done by the NASA Apollo 17 mission, following the paths taken by the astronauts. Figure 2 has a photograph of the lunar surface map and marker sticks, in which the square markers are used for identifying the position of the map and sticks in visual tracking, and they work as commands to control visualization. We briefly describe exploration activities during the Apollo 17 mission before going into the design and implementation of the lunar surface browsing system.

\subsection{Apollo 17 mission}

Apollo 17 was a manned-exploratory mission done

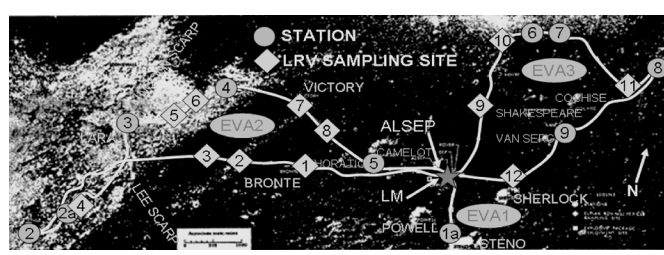

Figure 3. Area Around Apollo 17 Landing Site.

in 1972 as part of the Apollo Project, and its main activities targeted geologic exploration, which is why we selected it for exhibit content. Three astronauts reached moon orbit, and two of them landed on the moon.

The lunar module (LM) landed in a valley in the Taurus-Littrow region. Three separate lunar surface excursions were conducted during their stay. In the early phase of the first excursion, a ground-commanded television camera and a high-gain antenna on the lunar rover were installed, and video signals were sent to the Houston space center. The astronauts conducted various scientific experiments during the excursions, spending roughly 22 hours outside the LM and traversing about $35 \mathrm{~km}$ with the rover. They collected nearly $110 \mathrm{~kg}$ of rock and soil samples from various areas of stratigraphic interest: light mantle, dark mantle, sub-floor, and massifs.

The navigation area for the browsing system is shown in Figure 3. The Apollo 17 preliminary science report ${ }^{(53)}$ contains huge amounts of data that are neither easy nor practical for laymen to fully comprehend. We selected several remarkable activities for our study that were performed during the three excursions and various episodes, e.g., where a fender extension was knocked off, a crater was named "Ballet", the initials of an astronaut's daughter were carved in moon rock, orange soil was discovered, and 4.5 billion-year-old rocks were sampled.

\subsection{Design}

\subsubsection{Requirements}

The lunar surface browsing system enables interaction techniques and visualization functions to be used to help users browse geographic information on a tabletop environment using map-based AR. Although it is important that multiple stakeholders should be consulted for successful design in specific museums, here, we took 
into account six main factors in system design, referring to general museum guidelines for effective exhibits ${ }^{(54,55)}$ and design guidelines for $3 \mathrm{D}$ user interfaces ${ }^{(56)}$.

(1) Physical interaction: The system should enable tangible interactions that allow visitors to access artifacts physically to gain rich experiences.

(2) Group interaction: It should support collaborative interaction between individuals in groups, since people tend to visit museums with companions.

(3) Usability: We cannot assume that all visitors will be comfortable using a computer with a mouse and keyboard. An alternative interface should be easy to use, easy to learn, and intuitive.

(4) Aesthetics: It is necessary for not only exhibits themselves to be attractive to visitors, but also for the user interface to be attractive in terms of both interaction and visualization.

(5) Rapid installation: The equipment for the system should be set up quickly and be easily maintained, because such installation and maintenance must often be done at night after museums have closed or on days museums are closed.

(6) Cost: Small- and medium-sized museums have recently encountered financial difficulties and have faced the situation where old exhibits cannot be replaced with new ones. The equipment used in the system should be reasonably priced, so that such museums will be able to manage their exhibits.

\subsubsection{Interaction techniques}

The browsing system used three interaction techniques: (1) A pointer was used for selecting areas of interest on the map by zooming and focusing, enabling points to be reliably selected from many others; (2) a slider was used for designating a range of distances along a path on the map by adjusting the length between two markers, enabling variable control of viewpoints; and (3) a local view was simulated at a designated point, enabling dynamic visualization from an egocentric viewpoint.

(1) Pointer: When a printed map has a huge amount of geographically embedded information, it is problematic to select the point from which information is to be retrieved. An easy solution is to use an AR Magic Lens interface to zoom in. However, although this technique is quick, it is difficult to accurately select objects ${ }^{(57)}$. This is because tiny movements, such as those due to quiver-

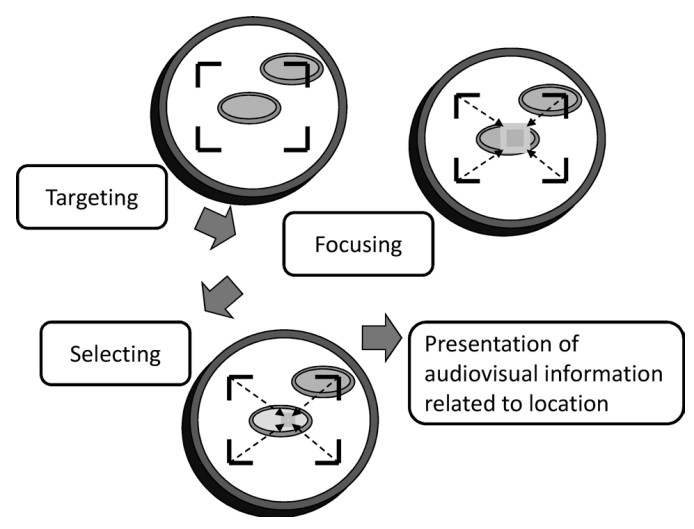

Figure 4. Steps in Selecting Point.

ing hands and the lens generating large variations from zoomed-in images, which is a problem common to actual lenses, both affect accuracy.

We took an approach to visualizing the selection process using the metaphor of a lens to select objects, focusing on the stability of selection. As seen in Figure 4 , the user first targets a point of interest by bringing it into the marker frame in the zoomed-in view. The lens then starts focusing on the point in the frame. A moment later, the point in the frame is selected, which is indicated by a color change in the point. Once the point is selected, tiny deviations in the lens position are ignored, resulting in a point being stably selected from many others by zooming and focusing.

(2) Slider: When a quantity or a volume is to be variably adjusted in the real world, a slider or a dial is generally used as the interface. An interaction technique similar to that using a slider has been applied to tangible AR applications to create 3D CG animations, i.e., two markers are brought closer together or moved further apart ${ }^{(58)}$. We took a similar approach to that using a slider to select a portion of the rover's route on the lunar surface map, as shown in Figure 5. The slider is comprised of two paper markers, and the length between them corresponds to the rover's path from the landing site. Users can select a portion of the route by adjusting the length between the two markers.

Here, we face the same problem as with the lens pointer: the total distance of the route is roughly $35 \mathrm{~km}$, and the sliding length is less than $35 \mathrm{~cm}$. A slight shift in the markers due to quivering hands or subtle fluctuations in the video image due to illumination conditions can 


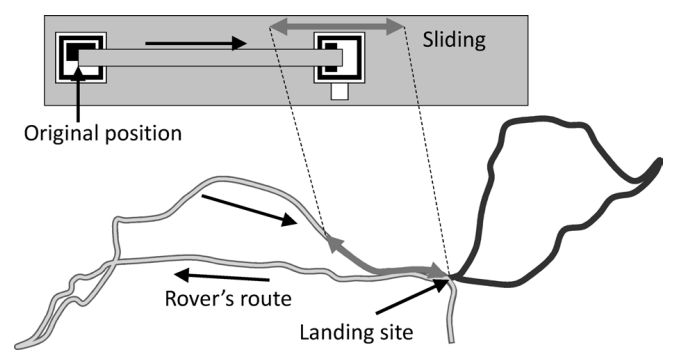

Figure 5. Slider for Selecting Portion of Rover Route.

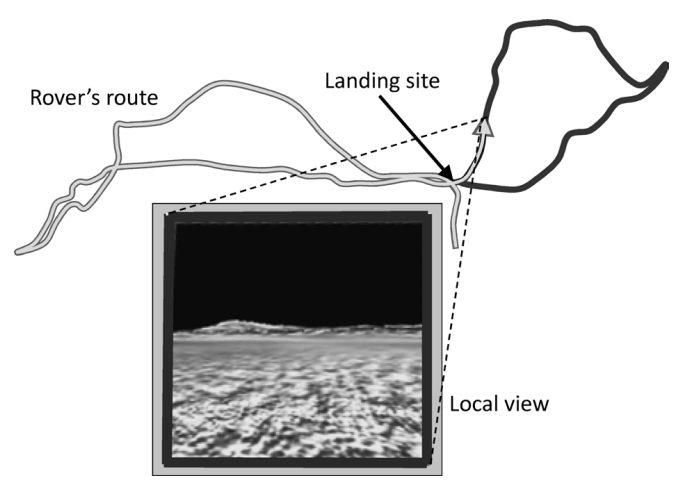

Figure 6. Local View Along Rover Route.

cause large variations in the selected location. A stabilizer is thus used for determining the position. When the distance between the two markers stays roughly within 3 pixels for two seconds, the location is fixed at the average value. The stabilizer prevents the viewpoint from fluctuating in the virtual world.

(3) Local view: Although a printed map displays an overview of the area, detailed information is limited to the resolution of the map. We can of course use another map enlarged to the area of interest. However, a printed map cannot provide dynamic information associated with various locations on the map. Our browsing system visualizes local views simulated at egocentric viewpoints, as shown in Figure 6. This interaction technique is similar to the image browsing used in augmented maps ${ }^{(38)}$. Rather than displaying a still image corresponding to the selected location, our browsing system produces animated views of the landscape.

This visualization plays a role in the focus and context functions, enabling users to view both the local landscape at the egocentric viewpoint and the overview
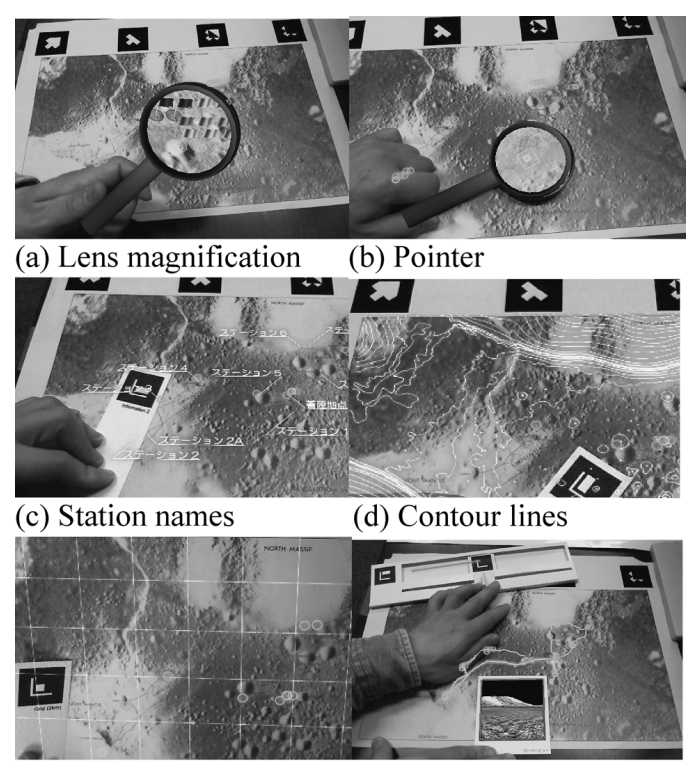

(e) Grid pattern

(f) Local view with slider

Figure 7. Visualization Functions.

of the area at the exocentric viewpoint simultaneously. The animations of the lunar surface landscapes from the astronaut's viewpoint along the rover's route give users a feeling of immersion and of being on the lunar surface riding in the rover.

\subsection{Implementation}

\subsubsection{Visualization functions}

The browsing system has several visualization functions including the ones provided by the interaction techniques we described in the previous section, controlled with commands from the marker sticks.

(1) Lenses: Two lenses are used for accessing the zoomin views of the lunar surface relief. Users pan one of them over the lunar surface map, reducing and increasing the zoom-in rate by changing the relative size of the lens marker (Figure 7 (a)). The other lens is used as a pointer to retrieve geographically embedded information by selecting a point of interest on the lunar surface map (Figure 7 (b)). Figure 8 has a photo of the rover and annotations on the extra-vehicular activities around the landing site. 


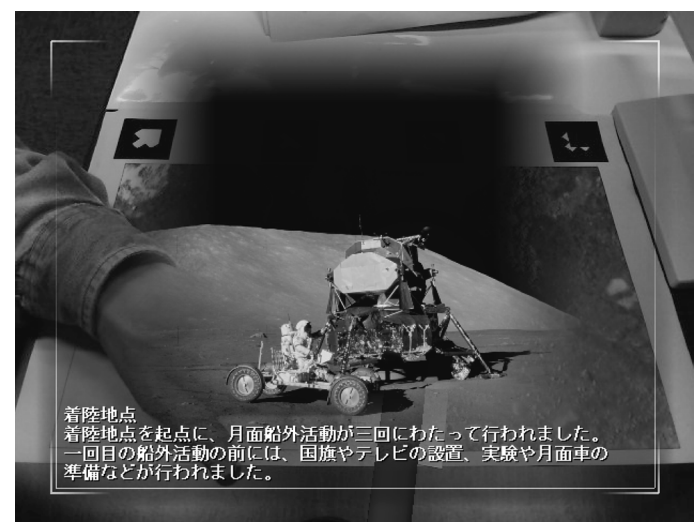

Figure 8. Photo and Annotations. "Landing site: Extra-vehicular activities were done three times. Flag, TV, experiment equipment, and lunar rover were set before first activity".

(2) Exploration data: The geographical data around the exploration area are overlaid on the lunar surface map. The data include the rover's route, the stations (Figure 7 (c)) where the rover stopped, and the craters near the route. Users can find their positions, names, and sizes.

(3) Contour: Transparent images of the elevation are overlaid on the lunar surface map with contour lines (Figure 7 (d)) or with a contour color map. Users can find the massifs northeast and southwest of the lunar surface.

(4) Grid: Blue grids are overlaid on the lunar surface map to present the scale of the exploration area (Figure 7 (e)). Users can roughly understand the extent of the lunar surface. The scale of each grid is set using a parameter file.

(5) Rover track: A miniature of the rover is presented that moves along the actual rover's route on the lunar surface map (Figure 7 (f)). The rover miniature is quite small on the map. Then, a lens enables users to see it on a larger scale.

(6) Local view: The view of the landscape from the rover's viewpoint is presented at another window in the video images (Figure 7 (f)). As the rover moves along the track, the landscapes are animated corresponding to the viewpoints along the route. The window of the local view is presented at the size of the local view marker.

(7) Slider: The position of the rover on the map changes with the distance between the slider markers (Figure 7 (f)). The local view enables users to view the landscape animations at viewpoints along the route designated with the slider.

\subsubsection{Configuration}

The software for the browsing system was installed on a PC equipped with a $2.8-\mathrm{GHz}$ Pentium IV CPU, 1 GB of memory, and an nVidia GeForce FX6800 graphics card with $256 \mathrm{MB}$ of video RAM. Video images were captured with a $640 \times 480$-pixel Web camera. The ARToolKit ${ }^{(59)}$ was used as a set of image processing libraries to capture the video images, detect the square markers in the images, track the positions and orientations of the markers, and recognize the patterns inside the markers.

This system used a parameter setting file to designate the text and audiovisual files as the geographically embedded information. A photograph of the TaurusLittrow region was used as a printed map, and topographic data were used to make the contour lines and contour map, which were obtained from satellite measurements. All the documents (including annotations, images, and sounds) were linked to corresponding locations.

An LCD monitor was used as a display device instead of an HMD because HMDs are not commonly used by most visitors to museums. A camera was statically mounted above a table in the tabletop AR environment roughly facing the same direction in which a user was viewing. Although one of the advantages of AR is viewpoint-based interaction that presents virtual objects based on the viewpoint of users, attaching a camera to their heads makes the scene unstable because they move their heads.

\section{Preliminary Experiment}

We performed a preliminary experiment to investigate the features of the tabletop AR environment in terms of not only efficiency but also suitability as an interface to science museums. The browsing system that we developed with map-based AR was evaluated as a tabletop AR environment in comparison with a typical geographic information viewer, i.e., the moon in Google Earth ${ }^{(60)}$ that was used as an application on a WIMP environment. The WIMP environment is considered as a standard user interface, since it is in general use with PCs. Figures 9 (a) and (b) show aspects of the manipula- 


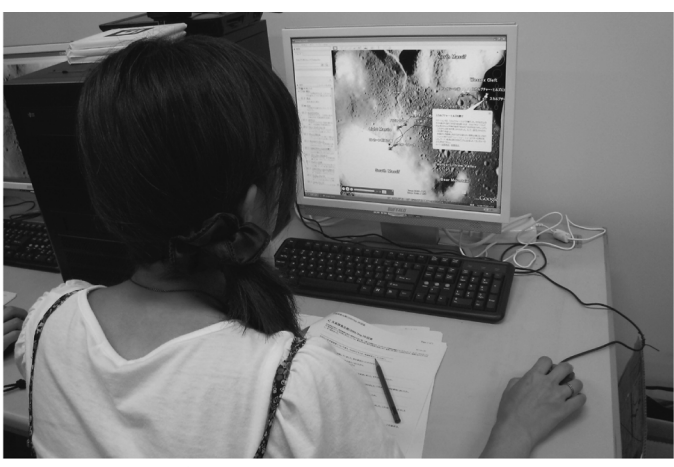

(a) WIMP environment

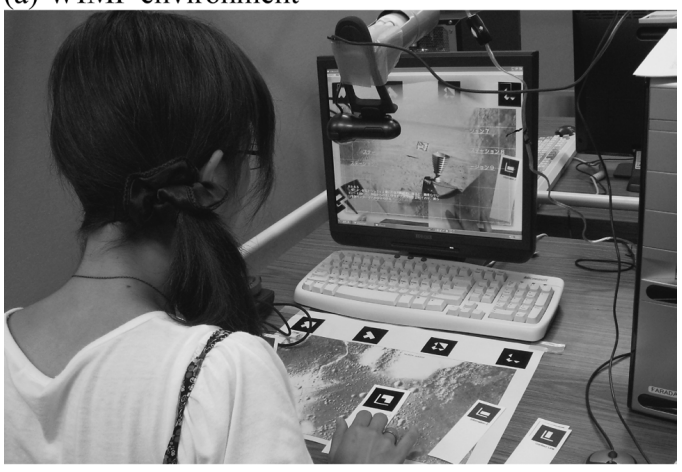

(b) Tabletop AR environment

Figure 9. Overview of Preliminary Experiment.

tion of navigation in the WIMP and tabletop AR environments.

\subsection{Method}

The WIMP and tabletop AR environments were compared in the experimental settings through tasks.

\subsubsection{Participants}

Sixteen students ( 8 females and 8 males, ages 18 to 27 years) participated in the experiment, but one female withdrew during the trial because she did not feel well. They came from various departments (in different universities) because visitors to science museums do not always like science or engineering. The university students were daily PC users who knew well the features on a WIMP environment. We believe that PC users familiar with a WIMP environment can appropriately find
Table 1. Characteristics of Participants in Preliminary Experiment.

\begin{tabular}{|l|c|}
\hline Characteristics & Number \\
\hline Gender & \\
\hline Male & 8 \\
\hline Female & 7 \\
\hline Frequency of computer use & 14 \\
\hline Every day & 1 \\
\hline A few times per week & 12 \\
\hline Experience with Google Earth & 3 \\
\hline Yes & \\
\hline No & 1 \\
\hline Experience with AR technology & 14 \\
\hline Yes & \\
\hline No & \\
\hline
\end{tabular}

the differences in features with a new environment, though the experiences may affect the results on usability. The characteristics of the participants are listed in Table 1. All the participants had normal vision and hearing.

\subsubsection{Materials}

The multimedia content that was presented as information for completing the tasks basically consisted of photographs and text annotations without sounds. We set up the moon in Google Earth so that it had the same functions as our lunar surface browsing system or the alternative functions. The visualization functions of the moon in Google Earth are described in Appendix A and are compared with those of our lunar surface browsing system. The moon in Google Earth did not have contour functions such as contour lines or a contour color map in our lunar surface browsing system. The tasks were designed to be completed with the alternative functions.

The participants' tasks were to answer quizzes while browsing the lunar surface in the WIMP and tabletop AR environments. Answering quizzes required participants to find a place related to the quiz on the lunar surface. Eight quizzes were prepared for the tasks in each environment. The quizzes are listed in Table 2. Three possible answers were presented for each quiz, and one of them was chosen by the participants. Figure 10 has setup schematics for: (a) the WIMP environment and (b) the tabletop AR environment. 
Table 2. Quizzes during Tasks in Preliminary Experiment.

\begin{tabular}{|c|c|}
\hline No. & Quiz \\
\hline \multicolumn{2}{|r|}{ Group 1} \\
\hline 1 & $\begin{array}{l}\text { Captain Cernan had experience with extra-space- } \\
\text { ship activities before the Apollo } 17 \text { mission. What } \\
\text { was the project's name? }\end{array}$ \\
\hline 2 & $\begin{array}{l}\text { There was an accident where the lunar rover's } \\
\text { fender broke. An astronaut tried to repair it imme- } \\
\text { diately. Why was the fender so important? }\end{array}$ \\
\hline 3 & $\begin{array}{l}\text { Captain Cernan saw an explosion of Styrofoam. } \\
\text { Why did it explode? }\end{array}$ \\
\hline 4 & $\begin{array}{l}\text { The first extra-vehicular activities were shortened. } \\
\text { What had taken up so much time before the activ- } \\
\text { ities? }\end{array}$ \\
\hline 5 & $\begin{array}{l}\text { An olivine was discovered at Station } 2 . \text { What era } \\
\text { was it formed in? }\end{array}$ \\
\hline 6 & $\begin{array}{l}\text { When Astronaut Schmitt got irritated, he calmed } \\
\text { down when he heard a joke about ballet. Why did } \\
\text { he get irritated? }\end{array}$ \\
\hline 7 & $\begin{array}{l}\text { What distance did the astronauts travel during the } \\
\text { second extra-vehicular activities? }\end{array}$ \\
\hline 8 & $\begin{array}{l}\text { How did you see the landscape from the lunar } \\
\text { rover when you were directed to the third extra- } \\
\text { vehicular activities? }\end{array}$ \\
\hline \multicolumn{2}{|r|}{ Group 2} \\
\hline 1 & $\begin{array}{l}\text { The Surface Electrical Properties experiment in- } \\
\text { volved overheating. What was the problem? }\end{array}$ \\
\hline 2 & $\begin{array}{l}\text { Astronaut Schmitt discovered colored soil. What } \\
\text { color was it? }\end{array}$ \\
\hline 3 & $\begin{array}{l}\text { Captain Cernan wrote the name "Tracy" in the } \\
\text { dust on the shelf of one side of a boulder. Who } \\
\text { was Tracy? }\end{array}$ \\
\hline 4 & $\begin{array}{l}\text { When Astronaut Schmitt descended the slope on } \\
\text { the Sculptured Hills, he pretended to do some- } \\
\text { thing. What was it? }\end{array}$ \\
\hline 5 & $\begin{array}{l}\text { The lunar rover was } 150 \mathrm{~m} \text { from the Lunar } \\
\text { Module before the astronauts left the lunar sur- } \\
\text { face. What was the purpose of that? }\end{array}$ \\
\hline 6 & $\begin{array}{l}\text { The astronauts said that they would like to share a } \\
\text { piece of rock with many other countries. What } \\
\text { did the rock become known as? }\end{array}$ \\
\hline 7 & $\begin{array}{l}\text { What distance did the astronauts travel during the } \\
\text { third extra-vehicular activity? }\end{array}$ \\
\hline 8 & $\begin{array}{l}\text { How did you see the landscape from the lunar } \\
\text { rover when you were directed to Steno Crater? }\end{array}$ \\
\hline
\end{tabular}

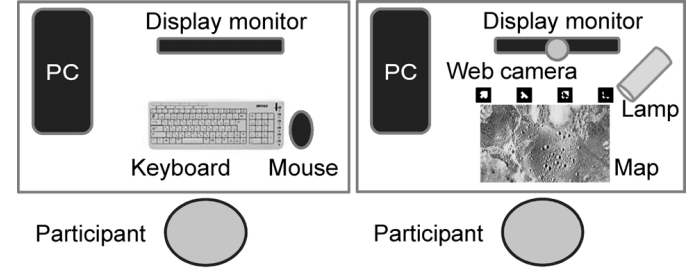

(a) WIMP

(b) Tabletop AR

Figure 10. Setups for Preliminary Experiment.

\subsubsection{Procedure}

Participants first read the instructions for the experiment so that they could fully understand the sequence. They were then instructed on how to manipulate the moon in Google Earth and our lunar surface browsing system. They had some time to practice in both environments before performing a series of tasks. When the participants felt comfortable in the environments, they proceeded to the task trials. They were required to complete the tasks as quickly and accurately as possible. To balance the effect of order in the environments, they were divided into two groups based on the sequence for the WIMP and tabletop AR environments, i.e., a participant had the WIMP for the first environment and he/she had the tabletop AR for the second environment. Different quizzes were asked for the different environments. There was a break of $15 \mathrm{~min}$ between trials in the first and second environments.

After they had finished the trials in both environments, a preference test was conducted using a Webbased system ${ }^{(61)}$. It mainly asked for their impressions of each environment and tried to measure the difficulty they had in comprehending topics on the lunar surface explorations. The question items are listed in Table 3. The ratings consisted of a five-point Likert scale ranging from one (strongly disagree) to five (strongly agree). Open-ended comments were required to provide complementary opinions. The participant's behaviors during the experiment were recorded on video.

\subsection{Results and discussion}

Table 4 lists the average values for the correct-answer rates and the completion times for the preliminary experiment. The values in parentheses are the standard 
Table 3. Questions in Preference Test in Preliminary Experiment.

\begin{tabular}{|c|l|}
\hline No. & \multicolumn{1}{|c|}{ Question items } \\
\hline 1 & The annotations were easy to read. \\
\hline 2 & The manipulations were easy. \\
\hline 3 & Experience was not needed. \\
\hline 4 & You felt as if you were on the moon. \\
\hline 5 & Tracing tracks were easy to manipulate. \\
\hline 6 & Controlling the viewpoint was easy. \\
\hline 7 & The relief was visible. \\
\hline 8 & It was suitable for science museums. \\
\hline 9 & It was suited to children. \\
\hline 10 & The bird's eye and local views were easy to see. \\
\hline 11 & The manipulation was enjoyable. \\
\hline 12 & The system was interesting. \\
\hline
\end{tabular}

Table 4. Correct-answer Rates and Completion Times in Preliminary Experiment.

\begin{tabular}{|l|c|c|}
\hline Environment & Rate [\%] & Time [s] \\
\hline WIMP & $99.2(3.2)$ & $801(196)$ \\
\hline Tabletop AR & $96.7(7.4)$ & $845(267)$ \\
\hline
\end{tabular}

Values in parentheses are standard deviations.

deviations. The results for the correct-answer rates imply that the difficulty of quizzes was balanced between the environments, and they were expected since all the quizzes could be answered correctly when the appropriate information was found. No statistically significant differences between the environments was observed in either parameter $(t(14)=1.146, p>0.01$ for the correct-answer rates or $t(14)=-0.524, p>0.01$ for the completion times).

Figure 11 plots the average score for each question in the preference test. The black bars indicate the WIMP environment and the white bars indicate the tabletop AR environment. The error bars correspond to the standard deviation.

A dependent $t$-test was conducted on the average score for each question. There were no significant differences in Questions 1, 4, 5, 6, 7, 8, 10,11, and 12, but there were significant differences in Questions 2 $(t(14)=3.309, p<0.01), 3(t(14)=2.965, p<0.01)$, and 9 $(t(14)=-3.696, p<0.01)$. The WIMP environment yielded better scores than the tabletop AR environment for both Questions 2 and 3, which asked for ease of use

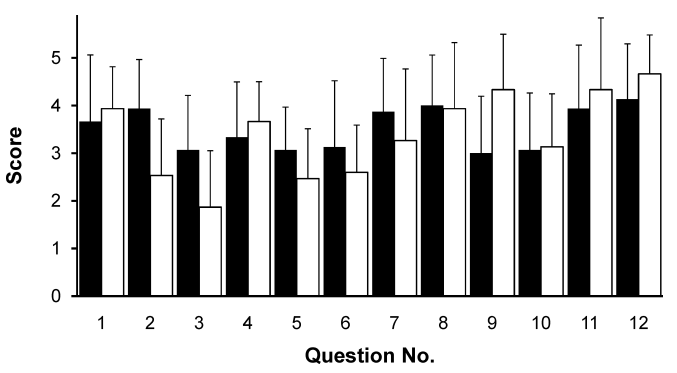

Figure 11. Results from Preliminary Experiment. (Black bars: WIMP, White bars: Tabletop AR).

and experience. The main reason for this was that the participants were likely very familiar with using a computer in the WIMP environment and $80 \%$ of the participants had experience with using Google Earth. However, they had only used the lunar surface browsing system we developed as a tabletop AR environment for the first time. Although time was allotted for participants to practice and become familiar with using the system before the trials, it was not sufficient to balance the environments.

Question 9 yielded better scores for the tabletop AR environment than for the WIMP environment. It revealed that participants had better impressions of it being more suitable to enabling children to browse the lunar surface. Although no significant differences were observed for Questions 8, 11, and 12 between the environments, the scores themselves were high at around or over 4 , which was interpreted as agreement that most participants had gained favorable impressions of the environments' suitability for science museums, playfulness as interfaces, and fun as systems.

The participants who had positive impressions in Question 9 scoring it 4 or 5 had positive impressions in Questions 11 and 12. This suggested that the main reason why the participants felt the tabletop AR environment was suited to children is that the tabletop AR environment had the factors of playfulness as interfaces and fun as systems. This was considered to lead to the positive impressions in Question 8. Eight out of fifteen participants stated in the open-ended comments that the system displaying and searching information with markers was interesting or enjoyable. Four out of fifteen participants stated that the lens function visualizing information on the lunar surface was interesting or enjoyable. 


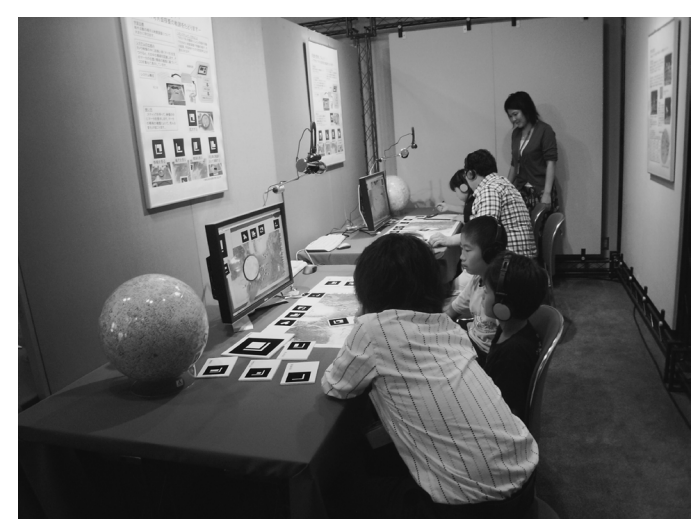

Figure 12. Photo of the Museum Exhibit and System Users.

\section{Practical Exhibit}

The preliminary experiment investigated the features of the tabletop AR environment compared to the WIMP environment by WIMP users. We obtained the results that the tabletop AR environment required some experience, but it would be suitable for use by children in science museums. However, most visitors come to science museums with companions such as family, which is quite different from the laboratory experiment condition. Therefore, an exhibit was prepared to investigate the properties and effectiveness of the lunar surface browsing system. The exhibit was held at the Chiba Museum of Science and Industry during a five-day holiday. Figure 12 has a snapshot of the museum exhibit.

\subsection{Methods}

The lunar surface browsing system utilizing the tabletop AR environment was used by visitors at the exhibit, and they evaluated it by completing tasks and answering questionnaires. We did not prepare another environment to compare with the tabletop AR environment, because we were advised by the staff of the science museum that it would be difficult for children to deal with computers that had mice and keyboards.

\subsubsection{Participants}

186 individuals or groups used the lunar surface browsing system, and learned about lunar surface explorations. Table 5 lists the attributes of museum goers who
Table 5. Attributes of Visitors.

\begin{tabular}{|c|c|}
\hline \multicolumn{2}{|c|}{$\begin{array}{l}\text { Did you come to the science museum with someone? Who } \\
\text { did you come with? }\end{array}$} \\
\hline Alone & $11(6.0 \%)$ \\
\hline Family & $148(79.6 \%)$ \\
\hline Only Children & 5 \\
\hline Child with parent(s) or grandparent(s) & 69 \\
\hline Children with parent(s) or grandparent(s) & 26 \\
\hline Couple & 1 \\
\hline No data on family structure & 47 \\
\hline Friend & $7(3.8 \%)$ \\
\hline Others & $1(0.5 \%)$ \\
\hline No answer & $19(10.1 \%)$ \\
\hline \multicolumn{2}{|c|}{ Did you know about NASA’s Project Apollo? } \\
\hline Yes & $72(38.7 \%)$ \\
\hline Child & 44 \\
\hline Adult & 24 \\
\hline No data on age & 4 \\
\hline No & $89(47.8 \%)$ \\
\hline Child & 82 \\
\hline Adult & 5 \\
\hline No data on age & 2 \\
\hline No answer & $25(13.5 \%)$ \\
\hline \multicolumn{2}{|l|}{ How often do you use a computer? } \\
\hline Every day & $35(18.8 \%)$ \\
\hline Child & 16 \\
\hline Adult & 18 \\
\hline No data on age & 1 \\
\hline 5-6 times per week & $10(5.4 \%)$ \\
\hline Child & 6 \\
\hline Adult & 4 \\
\hline A few times per week & $33(17.7 \%)$ \\
\hline Child & 26 \\
\hline Adult & 6 \\
\hline No data on age & 1 \\
\hline Less than once per week & $41(22.0 \%)$ \\
\hline Child & 38 \\
\hline Adult & 3 \\
\hline Never & $59(31.7 \%)$ \\
\hline Child & 55 \\
\hline Adult & 2 \\
\hline No data on age & 2 \\
\hline No answer & $8(4.4 \%)$ \\
\hline
\end{tabular}




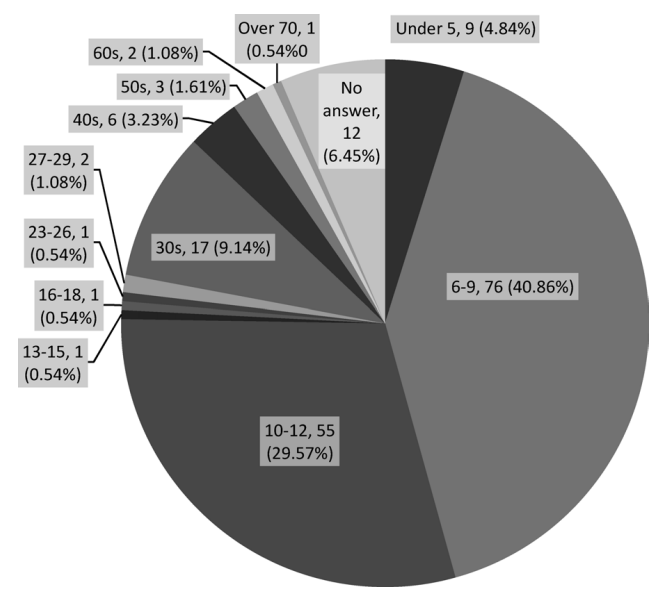

Figure 13. Age Distribution for Visitors at the Exhibit.

came to the exhibit. The data were based on questionnaires administered to visitors who evaluated the exhibit. When a visitor came to the exhibit alone, he/she evaluated the exhibit and answered the questionnaires including the surveys. When they came to the exhibit with their companions, they evaluated the exhibit as a group. We did not designate who should respond to the questionnaires, but we made space available on the forms for them to write down who had answered the surveys. Therefore, the survey was answered by one person within a family. For example, when a child answered the survey, the parent(s) did not. On the other hand, when a parent answered the survey, the child did not. An assistant supported every individual or group in using the system and performing the tasks based on the situation. The results from the first question supported the general tendency that people often visit museums with their families. The family group is classified in four cases; only children, a child with parent(s) or grandparent(s), children with parent(s) or grandparent(s), and a couple. Figure 13 is a pie chart of the age distribution for the visitors. This chart was drawn based on the ages of the visitors themselves who answered the surveys, not counting their companions. Most visitors were elementary school students and their parents who represent the typical age layers of visitors to science museums. We separated the visitors into two groups: children and adults in order to analyze the data on age dependency. Participants under 22 years old were categorized as children, and the ones over 22 years old were categorized as
Table 6. Quizzes in Tasks at Exhibit.

\begin{tabular}{|c|l|}
\hline No. & \multicolumn{1}{|c|}{ Quiz } \\
\hline 1 & $\begin{array}{l}\text { Astronaut Schmitt discovered colored soil. What } \\
\text { color was it? }\end{array}$ \\
\hline 2 & $\begin{array}{l}\text { When Astronaut Schmitt descended the slope on } \\
\text { the Sculptured Hills, he pretended to do some- } \\
\text { thing. What was it? }\end{array}$ \\
\hline 3 & $\begin{array}{l}\text { The lunar rover was 150 m from the Lunar } \\
\text { Module before the astronauts left the lunar sur- } \\
\text { face. What was the purpose of that? }\end{array}$ \\
\hline 4 & $\begin{array}{l}\text { What distance did the astronauts travel on the } \\
\text { lunar surface during all extra-vehicular activities? }\end{array}$ \\
\hline 5 & $\begin{array}{l}\text { How did you see the landscape from the lunar } \\
\text { rover when you were directed to the third extra- } \\
\text { vehicular activities (toward the north from the } \\
\text { landing site)? }\end{array}$ \\
\hline
\end{tabular}

adults.

\subsubsection{Materials}

The same content as that for the preliminary experiment was used at the exhibit, but the annotations were narrated for children through headphones instead of placing Kana alongside Kanji. Audio recordings of the communication between the astronauts and between the astronauts and the ground commanders were reproduced to create the feeling visitors were on the lunar surface.

The tasks of answering quizzes were also prepared to provide learning/game-playing aspects to visitors when they browsed the lunar surface. Visitors needed to find places related to the quizzes on the lunar surface when they answered. Five quizzes selected from those in the preliminary experiment were modified for the task, based on the advice from the curators. The quizzes are listed in Table 6. Three possible answers were presented for each quiz, and one of them was chosen by the visitors.

The setup for the tabletop AR environment was also the same as that for the preliminary experiment. A moon globe was provided to show visitors where the landing site for the Apollo 17 missions was. A larger lunar surface map was used to improve the visibility of the lunar surface map and make pointing more stable at positions on the map. Descriptions of the NASA Apollo missions and manuals on the system were displayed on the walls, so that visitors could better understand the 


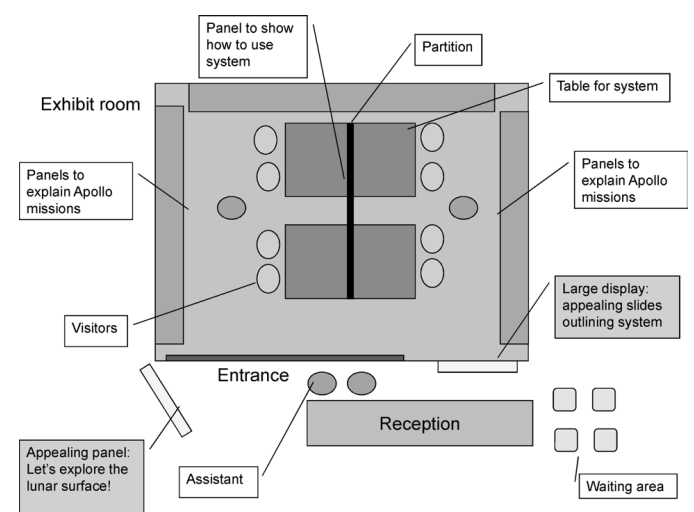

Figure 14. Layout for Four Systems at the Exhibit.

various details on these. Assistants were assigned to the lunar surface browsing systems to assist visitors in using them or helping them to understand the lunar surface explorations.

Figure 14 shows the layout for the exhibit at the Chiba Museum of Science and Industry. Four sets of browsing systems were provided to allow four groups of visitors to use the browsing systems simultaneously.

\subsubsection{Procedure}

First, the visitors were told about the purpose of the exhibit and given an overview of the lunar surface explorations. An assistant explained how to use the lunar surface browsing system, and guided them to the tasks of answering quizzes based on information that they had browsed with the system. The visitors then began browsing information embedded in the lunar surface themselves, and answering quizzes. Time limitations were not set for the tasks at the exhibit. The assistants helped visitors answer the quizzes based on the situation, but did not provide them with the correct answers.

A preference test was conducted after they had finished the tasks. The visitors were required to rate each of the question items listed in Table 7, based on their experience. The questions were classified into four categories of motivation (1, 2, 3, and 4), usability (5, 6, and 7), comprehension (8 and 9), and media capability (10, 11, and 12). The ratings consisted of four ranges of 1) strongly disagree, 2) disagree a little, 3) agree a little, and 4) strongly agree, trying to avoid intermediate ratings. Open-ended comments were obtained as comple-
Table 7. Questions in Preference Test at Exhibit.

\begin{tabular}{|c|c|}
\hline No. & Question items \\
\hline 1 & Did you enjoy the lunar surface navigation? \\
\hline 2 & Did you enjoy learning about the lunar surface? \\
\hline 3 & $\begin{array}{l}\text { Did you think you wanted to learn more about } \\
\text { the moon and space exploration? }\end{array}$ \\
\hline 4 & $\begin{array}{l}\text { Did you think the system was suitable for fami- } \\
\text { lies or children and parents to enjoy learning? }\end{array}$ \\
\hline 5 & $\begin{array}{l}\text { Did you feel it was easier to use the interface } \\
\text { than a PC with a mouse and keyboard? }\end{array}$ \\
\hline 6 & $\begin{array}{l}\text { Did you more easily understand how to use the } \\
\text { interface than a PC with a mouse and keyboard? }\end{array}$ \\
\hline 7 & $\begin{array}{l}\text { Did you enjoy using the interface more than a PC } \\
\text { with a mouse and keyboard? }\end{array}$ \\
\hline 8 & $\begin{array}{l}\text { Did you comprehend the purpose of the Apollo } \\
\text { missions? }\end{array}$ \\
\hline 9 & $\begin{array}{l}\text { Did you comprehend the geology of the lunar } \\
\text { surface? }\end{array}$ \\
\hline 10 & Did you read the annotations? \\
\hline 11 & Did you listen to the narration? \\
\hline 12 & $\begin{array}{l}\text { Were the voices of the astronauts in communica- } \\
\text { tion useful for comprehending the situation with } \\
\text { the lunar surface explorations? }\end{array}$ \\
\hline
\end{tabular}

mentary opinions. A gift, which was a papercraft of the moon, was given to visitors after they had finished the preference test.

\subsection{Results and discussion}

Table 8 lists the correct-answer rates for quizzes in tasks at the exhibit. The correct-answers exceeded $90 \%$ in Quizzes 1, 2, and 3, but dropped off in Quizzes 4 and 5 . The former quizzes could be answered correctly with photographs and annotations, but the latter required visitors to guess the answers from the grid scale and landscapes. A particular mistake was observed in Quiz 4 where some visitors thought a round-trip travel was one way.

Figure 15 plots the total count rated for the question items in the preference test, disregarding dependence on participants' attributes except ages. Most visitors including both children and adults gained positive impressions from the exhibit in terms of motivation. Questions 1, 2, 3, 4, and 7 especially, attracted positive impressions of over $80 \%$ in both children and adults; 
Table 8. Correct-Answer Rates at Exhibit.

\begin{tabular}{|c|c|}
\hline Quiz No. & Rate [\%] \\
\hline 1 & 97.8 \\
\hline 2 & 96.7 \\
\hline 3 & 95.2 \\
\hline 4 & 64.0 \\
\hline 5 & 84.4 \\
\hline
\end{tabular}

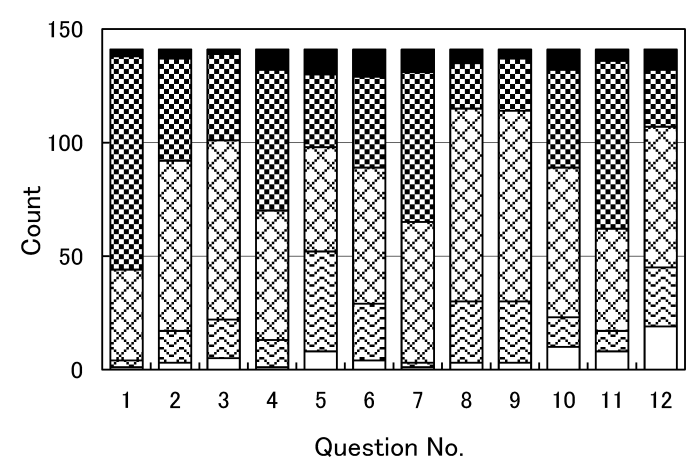

(a) Children

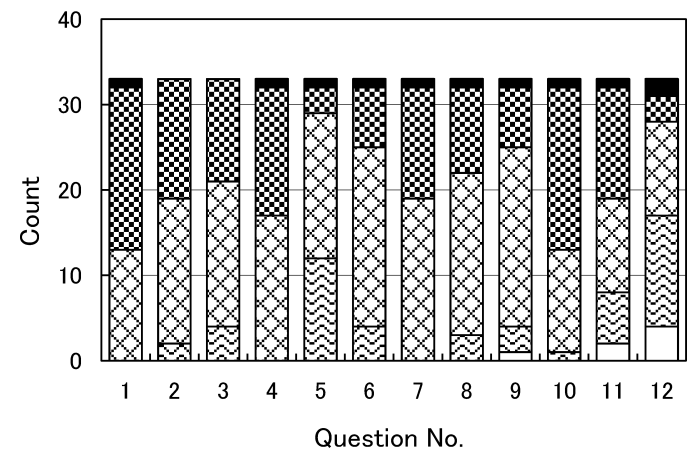

(b) Adults

Figure 15. Results from Exhibit. (White areas: strongly disagree, Wavy areas: slightly disagree, Cross-hatched areas: slightly agree, Dotted areas: strongly agree, Black areas: no answer)

these were correlated to enjoyed exploration, enjoyed learning, initiative, suitability, and enjoyment of the interface, respectively. However, Questions 5 and 12 attracted positive impressions that were lower than $65 \%$ in both children and adults; these were related to the ease of use and the usefulness of the communication voice.
Table 9. Average Scores for Exhibit.

\begin{tabular}{|c|c|c|}
\hline Question No. & \multicolumn{2}{|c|}{ Scores } \\
\hline & Children & Adults \\
\hline 1 & $3.64(0.56)$ & $3.59(0.50)$ \\
\hline 2 & $3.18(0.72)$ & $3.36(0.60)$ \\
\hline 3 & $3.08(0.73)$ & $3.24(0.66)$ \\
\hline 4 & $3.36(0.68)$ & $3.47(0.51)$ \\
\hline 5 & $2.78(0.89)$ & $2.72(0.63)$ \\
\hline 6 & $3.05(0.79)$ & $3.09(0.59)$ \\
\hline 7 & $3.47(0.57)$ & $3.41(0.50)$ \\
\hline 8 & $2.90(0.66)$ & $3.22(0.61)$ \\
\hline 9 & $2.93(0.67)$ & $3.06(0.67)$ \\
\hline 10 & $3.08(0.85)$ & $3.56(0.56)$ \\
\hline 11 & $3.36(0.85)$ & $3.09(0.93)$ \\
\hline 12 & $2.70(0.94)$ & $2.42(0.85)$ \\
\hline
\end{tabular}

Values in parentheses are standard deviations.

That is, the question items related to the enjoyments obtained highly positive impressions, while the question items related to the usability and media capability received less positive responses.

Table 9 lists the average scores of children and adults, eliminating the data with no answer. The values in parentheses are the standard deviation. A $t$-test was conducted on the average scores for each question. There was a statistically significant difference $(t(161)=$ $3.80, p<0.01)$ between children and adults in only Question 10 asking if the visitor read the annotations. The average score of the children was lower than that of the adults. This was interpreted as difficulty in reading the annotations for the children, because Kanji characters were included in the annotations. However, we think that this difficulty has been compensated with the narration according to the results of Questions 9 (asking about comprehension of the content) and 11 (asking about listening to the narration) that did not have large differences between children and adults. Even the children tended to listen to the narration carefully; we observed that the children gave Question 11 positive impressions, scoring it 4 , more than the adults, though there was no significant difference between them. There was a tendency toward significant difference $(t(164)=$ 2.53, $p<0.05$ ) between children and adults in Question 8 asking if the visitor comprehended the purpose of the Apollo missions. This suggested that the adults under- 
stood the purpose of the Apollo missions better than the children. It was not sufficient to just use the lunar surface browsing system in order to understand it, and it required reading the descriptions on the Apollo mission at the panels. According to the observations, we guessed that the adults tried to study more about the Apollo missions with the wall panels in the exhibit, while the children were not so interested in the descriptions of the panels, focusing on the browsing system.

Although no significant differences were found between children and adults in terms of enjoyment related to Questions 1 and 2, the positive impressions exhibited a slightly different tendency for children and adults. Question 1 had a higher rate of "strongly agree", and Question 2 had a decreased rate with an increased rate for "slightly agree". This tendency was found more in children, which was manifested in a trend suggesting that children enjoyed manipulating the lunar surface browsing system, whereas adults enjoyed the exhibition content itself on the NASA Apollo mission. The observations indicated map-based AR provided refreshing and magical experiences to children. Their parents were quite captivated by the mysteries of the moon and surprised to learn afresh that the explorations with mannedmissions had already been done roughly four decades ago.

Even though no significant differences were also not observed in the series of questions on usability (Questions 5, 6, and 7) between children and adults, highly positive impressions scoring them 4 were made more by the children than by the adults. This suggests that the children felt more than the adults that it was easy to use the system visualizing information with markers, and it was intelligible, and enjoyable.

Shortcomings with the tabletop AR environment were reported through the open-ended comments. Three visitors pointed out that it was necessary to become accustomed with how to use the browsing system with marker sticks. One of them pointed out that the WIMP environment was easier than the tabletop AR environment for using these kinds of applications. Other negative opinions were that too many marker sticks would confuse users in choosing appropriate commands and that the system response was a little slow compared to the general applications on PCs.

\section{General Discussion}

Overall, the preliminary experiment revealed that the tabletop AR environment was preferred to that of the WIMP in terms of its suitability for children, and not in its ease of use and experience. The exhibit at the Chiba Museum of Science and Industry demonstrated a tendency that the children enjoyed more manipulating the lunar surface browsing system, and the adults enjoyed more studying the Apollo missions. We suggest interpretations for these findings and discuss the properties of our lunar surface browsing system below.

\subsection{Usability as user interface}

The results from the preference test in the preliminary experiment suggested that the tabletop AR environment was suitable for children, but it was not very easy to use and required some experience. At first sight, however, the suitability for children is inconsistent with the difficulty of use and the requirement of experience. Two participants pointed out in the preliminary experiment that although the tabletop AR environment was enjoyable, the WIMP environment was better for users who had become accustomed to PCs with a mouse and keyboard. This was interpreted as a general issue in that attributes of users tended to dominate usability on the user interface. This trend was consistent with that at the practical exhibit. Questions 5, 6, and 7, which were related to the usability of the preference test in the practical exhibit, gained more highly preferable impressions (strongly agree) from children not likely being accustomed to the WIMP than from adults likely being accustomed to the WIMP, though no statistically significant differences have been found in the average scores between children and adults.

The negative impressions about experience were predictable considering the necessity for experience with a new user interface in a tabletop AR environment. We considered that the necessity for experience influenced user impressions on the ease of use, but it would be bridged over with some experience.

It is likely that the visualization functions we implemented in the lunar surface browsing system allowed manipulation to be enjoyable based on the results for Question 7 related to enjoyment at the practical exhibit. Many positive open-ended comments were obtained 
from the visitors in the exhibit, e.g., "The lens function was interesting", "The system was wonderful", and "I enjoyed manipulating the system a lot". The observations suggested that the pop-up presentations of photographs and annotations with the lens pointer thrilled and surprised visitors, and the local view of the landscape from the viewpoint of the rover gave visitors a realistic sensation of being on the lunar surface.

Consequently, it seems reasonable to conclude that although the tabletop AR environment provided in the lunar surface browsing system is not suitable for WIMP users under the situation requiring efficiency, it would be usable for people who have not become accustomed to the WIMP under the situation requiring enjoyments such as experiences in science museums. However, it is noteworthy that one participant in the preliminary experiment reported that he could enjoy the lens pointing function until he got used to it, but became irritated after that. The lens pointer is not considered suitable for a user interface for applications that demand efficiency, even though it creates playful and aesthetic interactions.

Various applications using tangible user interfaces have been developed as proof-of-concept applications ${ }^{(56)}$, enabling us to naturally and intuitively interact with virtual objects by handling their physical counterparts. However, the interface-design concept provides no proof of being effective or useful in practical situations. Although the results from the preliminary experiment and the practical exhibit suggested that the tabletop AR environment offered playful and aesthetic interactions, they did not provide any evidence the tabletop AR environment could be extended to have a relation with learning effectiveness in museums.

\subsection{Effectiveness as exhibit}

The results obtained from the preference test at the exhibit suggested that our lunar surface browsing system using a tabletop AR environment enabled the exhibit to be enjoyable, motivational, and offer cooperative elements. Observations of visitors' experiences at the exhibit suggest that children enjoyed navigating the lunar surface more, and adults enjoyed learning about lunar surface explorations more. Three parents pointed out in the open-ended comments, that "I enjoyed the exhibit more than the kids, and wanted to extend my experiences". Two parents reported that "it was slightly difficult for children to understand the lunar surface explo- rations, though they enjoyed navigating the lunar surface". We also observed that parents tried to enthusiastically explain the exploration activities to their children.

The high rates of positive impressions on the suitability of the exhibit for learning with families suggested that the tabletop AR environment facilitated collaborative interactions between children and parents. We observed divided behaviors where children manipulated the browsing system and parents navigated the lunar surface. Our lunar surface browsing system encouraged children to contribute to their experiences and become capable of sharing and constructing knowledge. The tabletop AR environment engendered much more exploration and reflection by learners with tangible interactions ${ }^{(62,63)}$, which established a foundation for both learning and enjoyment. We may go on from this to the conclusion that the tabletop AR environment encouraged active behaviors by visitors through communication and collaboration when visualization techniques and learning materials were appropriately designed.

Our lunar surface browsing system was designed as a tabletop environment using map-based AR to satisfy the requirements for physical interaction, group interaction, usability, and aestheticity. Although the system allowed visitors to hold marker sticks and to point out locations on the printed map, views may meet with negative responses that the system did not fully use the features of a tangible user interface. However, the interaction techniques in the system were considered to have contributed to the enjoyability of the exhibit. A lunar globe placed alongside the lunar surface map also played a role in physical interactions, enabling the geometric relationship between the moon and the exploration area to be understood. It is important that the system is implemented appropriately as a part of exhibits.

Our lunar surface browsing system was originally designed to satisfy the requirements for rapid installation and cost. We could set up the exhibit within a day, including work on assembling the system, arranging the lighting conditions, and placing panels on the walls. Actually, this rapid installation pleased the staff of the science museum, because no other exhibitions were affected in their schedule. Further, as only a PC, a Web camera, and paper were required to implement the system, it was very economical, excluding the cost for system development. 


\section{Conclusion}

We developed a lunar surface browsing system with a tangible user interface by using augmented reality technology. It creates an interactive tabletop environment where learners can intuitively learn about lunar surface exploration from a printed map and multimedia projections. Two experiments were performed to investigate the properties of the lunar surface browsing system. The first was a preliminary in our laboratory which revealed that the lunar surface browsing system would be suitable as an interactive environment to promote children's learning. The second experiment suggested that the lunar surface browsing system would provide a learning environment where children and their parents could take the initiative of learning together. Our experiments did not target the effect of learning, which will be investigated in future work on the tabletop AR environment.

\section{Acknowledgments}

We are grateful to the staff of the Chiba Museum of Science and Industry (http://www.chiba-muse.or.jp/SCIENCE/) for giving us an opportunity to exhibit some fruits of our research.

\section{References}

(1) Falk, J. H. and Dierking, L. D.: The Museum Experience. Whalesback Books, Washington, D.C. (1992).

(2) Umiker-Sebeok, J.: "Behavior in a museum: a semio-cognitive approach to museum consumption experiences. Signifying behavior", J. of Research in Semiotics, Communication Theory, and Cognitive Science, Vol. 1, pp. 52-100 (1994).

(3) Hooper-Greenhill, E.: Museum and Gallery Education, Leicester University Press London, Leicester (1994).

(4) Usaka, T., Yura, S., Fujimori, K. et al.: "A multimedia MUD system for the digital museum", Proc. 3rd AsiaPacific Computer Human Interaction, pp. 32-37 (1998).

(5) Falk, H. J. and Dierking, L. D.: Learning from Museums: Visitors Experience and the Making of Meaning, Rowman \& Littlefield, New York (2000).

(6) Csikszentmihalyi, M. and Hermanson, K.: "Intrinsic motivation in museums: Why does one want to learn?", in Public Institutions for Personal Learning: Establishing a Research Agenda, eds. Falk, J. H. and Dierking, L. D.
Washington, D.C., pp. 67-77, American Association of Museums (1995).

(7) Adams, M., Luke, J. and Moussouri, T.: "Interactivity: Moving beyond terminology", Curator: The Museum J., Vol. 47, pp. 155-170 (2004).

(8) Wakkary, R. and Hatala, M.: "Situated play in a tangible interface and adaptive audio museum guide", Perspective Ubiquitous Computing, Vol. 11, pp. 171-191 (2007).

(9) Hope, T., Nakamura, Y., Takahashi, T. et al.: "Familial collaboration in a museum", Proc. of the ACM Conference on Human Factors in Computing Systems (CHI 2009), pp. 1963-1972 (2009).

(10) Asai, K., Kondo., T., Kobayashi, H. et al.: "A geographic surface browsing tool using map-based augmented reality", Proc. of International Conference Visualization, pp. 93-98 (2008).

(11) Kato, H., Billinghurst, M., Poupyrev, I. et al.: "Virtual object manipulation on a table-top AR environment", Proc. of International Symposium on Augmented Reality, pp. 111-119 (2000).

(12) Regenbrecht, H., Baratoff, G. and Wagner, M. T.: "A tangible AR desktop environment", Computer \& Graphics, Vol. 25, pp. 755-763 (2001).

(13) Kiyokawa, K., Billinghurst, M., Hayes, S. E. et al.: "Communication behaviors of co-located users in collaborative AR interfaces", Proc. of International Symposium on Mixed and Augmented Reality (ISMAR 2002), pp. 139-148 (2002).

(14) Bannon, L., Benford, S., Bowers, J. et al.: "Hybrid design creates innovative museum experiences", Communications of the ACM, Vol. 48, pp. 62-65 (2005).

(15) Bimber, B., Coriand, F., Kleppe, A. et al.: "Superimposing pictorial artwork with projected imagery", IEEE Multimedia, Vol. 12, pp. 16-26 (2005).

(16) Koleva, B., Egglestone, S. R., Schnadelbach, H. et al.: "Supporting the creation of hybrid museum experiences", Proc. of ACM Conference on Human Factors in Computing Systems, pp. 1973-1982 (2009).

(17) Asai, K., Kobayashi, H., Kondo, et al.: "Subjective evaluation of a lunar surface browsing tool using map-based AR", Proc. of Int. Conf. on Computers in Education, pp. 749-753 (2008).

(18) Asai, K.: "Visualization Based on Geographic Information in Augmented Reality", in The Horizon of Virtual and Augmented Reality: The Reality of the Global Digital Age, ed. Soha, M., pp. 185-204, In-Tech Education and Publishing, Rijeka (2010).

(19) Hashimoto, M.: "GeoMovie Creator (GMC): authoring 
tool for creating 3D educational contents", Proc. Information Processing Sciety of Japan (2004).

(20) NASA Apollo missions. http://www.nasa.gov/mission_ pages/apollo/index.html

(21) Schmalstieg, D. and Wagner, D.: "Experiences with augmented reality", Proc. of International Symposium on Mixed and Augmented Reality (ISMAR 2007), pp. 3-15 (2007).

(22) Damala, A., Cubaud, P., Bationo, A. et al.: "Bridging the gap between the digital and evaluation of a mobile augmented reality guide for the museum visit", Proc. of International Conference on Digital Interactive Media in Entertainment and Arts, pp. 120-127 (2008).

(23) Miyashita, T., Meier, P., Tachikawa, T. et al.: "An augmented reality museum guide", Proc. of the IEEE International Symposium on Mixed and Augmented Reality (ISMAR 2008), pp. 103-105 (2009).

(24) Kondo, T., Manabe, M., Arita-Kikutani, H. et al.: "Practical uses of mixed reality exhibition at the National Museum of Nature and Science in Tokyo", Proc. of the Joint Virtual Reality Conference of EGVE-ICAT-EuroVR, pp. 27-28 (2009).

(25) Rocchi, C., Stock, O., Zancanaro, M. et al.: "The museum visit: generating seamless personalized presentations on multiple devices", Proc. of the ACM International Conference on Intelligent User Interfaces (IUI 2004), pp. 316-318 (2004).

(26) Roes, I., Stash, N., Wang, Y. et al.: "A personalized walk through the museum: the CHIP interactive tour guide", Proc. of the ACM Conference on Human Factors in Computing Systems (CHI 2009), pp. 3317-3322 (2009).

(27) Hsi, S. and Fait, H.: "RFID enhances visitor's museum experience at the Exploratorium", Communications of the ACM, Vol. 48, pp. 60-65 (2005).

(28) Hornecker, E. and Stifter, M.: "Digital backpacking in the museum with SmartCard", Proc. of the ACM New Zealand Chapter's International Conference on ComputerHuman Interaction, pp. 99-107 (2006).

(29) Brown, B., MacColl, I., Chalmers, M. et al.: "Lessons from the Lighthouse: collaboration in a shared mixed reality system", Proc. of the ACM Conference on Human Factors in Computing Systems, pp. 577-584 (2003).

(30) Yatani, K., Sugimoto, M. and Kusunoki, F.: "Musex: a system for supporting children's collaborative learning in a museum with PDAs", Proc. of IEEE International Workshop on Wireless and Mobile Technologies in Education (WMTE 2004), p.109 (2004).

(31) Klopfer, E., Perry, J., Squire, K. et al.: "Mystery at the museum - a collaborative game for museum education", Proc. of the ACM Conference on Computer Support for Collaborative Learning, pp. 316-320 (2005).

(32) Grinter, R. E., Aoki, P. M., Hurst, A. et al.: "Revisiting the visit: understanding how technology can shape the museum visit", Proc. of the ACM Conference on Computer Supported Cooperative Work (CSCW 2002), pp. 146-155 (2002).

(33) Kuflik, T., Sheidin, J., Jbara, S. et al.: "Supporting small groups in the museum by context-aware communication services", Proc. of International Conference on Intelligent User Interface (IUI 2007), pp. 305-308 (2007).

(34) Kortbek, K. J. and Gronbek, K: "Interactive spatial multimedia for communication of art in the physical museum space", Proc. of the ACM Conference on Multimedia (MULTIMEDIA 2008), pp. 609-618 (2008).

(35) Leinhardt, G. and Knutson, K.: Listening in on museum conversations, AltaMira Press, Walnut Creek (2004).

(36) Ciolfi, L. and Bannon, L.: "Designing interactive museum exhibits: enhancing visitor curiosity through augmented artifacts", Proc. of European Conference on Cognitive Ergonomics, pp. 311-317 (2002).

(37) Schmalstieg, D. and Reitmayr, G.: "Augmented reality as a medium for cartography", in Multimedia Cartgraphy, eds. Cartwright, W., Peterson, M. and Gartner, G., pp. 267-282, Springer-Verlag, Heidelberg (2006).

(38) Bobrich, J. and Otto, S.: "Augmented maps", Proc. of Symposium on Geospatial Theory, Processing, and Applications, in IAPRS, 34, part 4 (2002).

(39) Reitmayr, G., Eade, E. and Drummond, T.: "Localisation and interaction for augmented maps", Proc. of International Symposium on Mixed and Augmented Reality (ISMAR 2005), pp. 120-129 (2005).

(40) Ishii, H., Ratti, C., Piper, B. et al.: "Bringing clay and sand into digital design - continuous tangible user interfaces”, BT Technology J., Vol. 22, pp. 287-299 (2004).

(41) Shelton, B. E. and Hedley, N. R.: "Using augmented reality for teaching Earth-Sun relationships to undergraduate geography students", Proc. of International Augmented Reality Toolkit Workshop (2002).

(42) Kaufmann, H.: "Construct3D: an augmented reality application for mathematics and geometry education", Proc. of the ACM International Conference on Multimedia (MULTIMEDIA 2002), pp. 656-657 (2002).

(43) Fjeld, M., Juchli, P. and Voegtli, B. M.: "Chemistry education: a tangible interaction approach", Proc. of INTERACT, pp. 287-294 (2003).

(44) Morita, Y., Setozaki, N. and Iwasaki, T.: "Developemnt 
and evaluation of a tangible learning system for astronomy education: A pilot study", Proc. of World Conference on Educational Multimedia, Hypermedia and Telecommunications, pp. 3666-3671 (2010).

(45) Duncan, C.: Civilizing Rituals: Inside Public Art Museums, Routledge (1995).

(46) Bell, G.: "Making sense of museums: the museum as 'Cultural Ecology", IntelLabs, pp. 1-17 (2002).

(47) Duffy, T. M. and Jonassen, D. (eds.): Constructivism and the Technology of Instruction: A Conversation, Lawewnce Erlbaum Associates Inc., Hillsdale, NJ (1992).

(48) Willis, J.: "The maturing of constructivist instructional design: some basic principles that can guide practice", Educational Technology, Vol. 40, pp. 5-16 (2000).

(49) Milgram, P. and Kishino, F.: "A taxonomy of mixed reality visual display“, IEICE Transactions on Information Systems, Vol. E77-D, pp. 1321-1329 (1994).

(50) Vom Lehn, D., Heath, C. and Hindmarsh, J.: "Exhibiting interaction: conduct and collaboration in museums and galleries", Symbolic Interaction, Vol. 24, pp. 189-216 (2001).

(51) Crowley, K., Callanan, M. A., Jipson, J. L. et al.: "Shared scientific thinking in everyday parent-child activity", Science Education, Vol. 85, pp. 712-732 (2001).

(52) Sanford, C., Knutson, K. and Crowley, K.: "We always spend time together on Sundays: how grandparents and their grandchildren think about and use informal learning spaces", Visitor Studies, Vol. 10, pp. 136-151 (2007).

(53) NASA: Apollo 17 Preliminary Science Report, SP-330 (1973).

(54) Dean, D.: Museum Exhibition: Theory and Practice, Routledge Press, New York (1994).

(55) Bitgood, S.: "Designing effective exhibits: criteria for success, exhibit design approaches, and research strategies", Visitor Behavior, Vol. 9, pp. 4-15 (1994).

(56) Bowman, D. A., Kruijff, E., LaViola, J. J. et al.: 3D User Interfaces: Theory and Practice, Addison-Wesley, Boston (2004).

(57) Looser, J., Billinghurst, M., Grasset, R. et al.: "An evaluation of virtual lenses for object selection in augmented reality", Proc. of International Conference on Computer Graphics and Interactive Techniques in Australia and Southeast Asia, pp. 203-210 (2007).

(58) Lee, G. A., Nelles, C., Billinghurst, M. et al.: "Immersive authoring of tangible augmented reality applications", Proc. of International Symposium on Mixed and Augmented Reality (ISMAR 2004), pp. 172-181 (2004).

(59) ARToolkit. HITLab, University of Washington: http:// www.hitl.washington.edu/artoolkit/

(60) Google Earth. Google: http://earth.google.com/

(61) REAS. The Open University of Japan: http://reas.code ouj.co.jp/

(62) Rogers, Y., Scaife, M., Gabrielle, S. et al.: "A conceptual framework for mixed reality environments: designing novel learning activities for young children", Presence: Teleoperators and Virtual Environments, Vol. 11, 677-686 (2002).

(63) Zuckerman, O., Arida, S. and Resnick, M.: "Extending tangible interfaces for education: digital montessori-inspired manipulatives", Proc. of the ACM Conference on Human Factors in Computing Systems, 859-868 (2005).

\section{A. Appendix: Visualization functions for moon in Google Earth}

As stated in the 'Preliminary Experiment' section, we set up the moon in Google Earth so that it could be compared with that in our lunar surface browsing system. Some alternative functions for the moon in Google Earth were prepared for the experiment, because these functions were not originally installed in Google Earth.

The whole scene for exploration by the NASA Apollo 17 mission, as seen in Figure A1 (a), corresponds to the lunar surface map in our lunar surface browsing system.

The lens had zoom-in and zoom-out functions. The moon in Google Earth could be zoomed smoothly by double-clicking the mouse, even though the icons at the upper right could be used to control the zoom (Figure A2 (a)).

The exploration data were presented through an annotation function, as shown in Figure A1 (b). Unfortunately, since the moon in Google Earth did not have a function for annotations to be added to the photographs, we used a preset annotation page to see the photographs, which involved English annotations with photographs, as seen in Figure A1 (c). The presentations could be accessed by double-clicking the white icon for Japanese annotations (Figure A2 (b)) and the red circle for preset annotations (Figure A2 (c)).

The grid provided scale to the lunar surface map. Although there is no grid for the moon in Google Earth, a reference scale was placed on the lunar surface to enable users to understand the scale.

The rover's track is presented with a black line on the moon in Google Earth. Although the moon in 


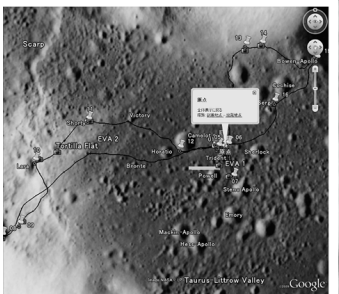

(a) Whole area

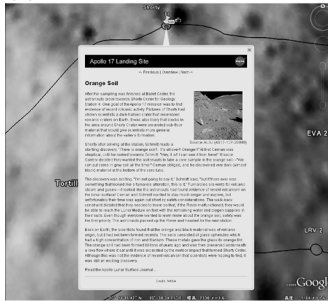

(c) Preset annotations

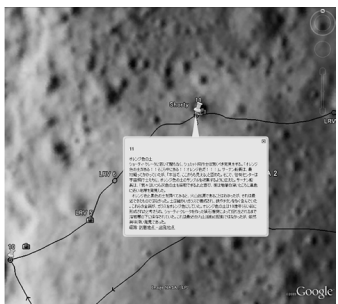

(b) Japanese annotations

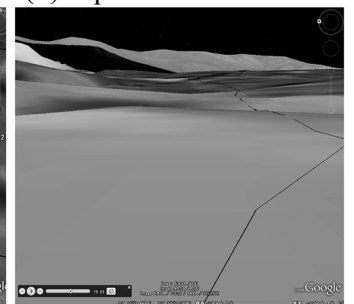

(d) Landscape

Figure A1. Screenshots of Moon in Google Earth.

Google Earth does not have a miniature of the rover, it has a function for moving along some preset route on the lunar surface.

The landscape from the rover's viewpoint could be

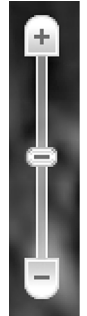

(a) - 100

(f)

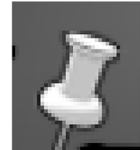

(b)

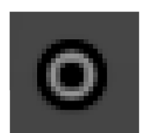

(c)

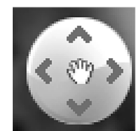

(d)

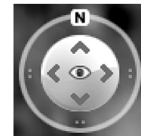

(e)
Figure A2. Icons for Moon in Google Earth. (a) zoom-in and zoom-out functions, (b) pop up Japanese annotations, (c) pop up preset annotations, (d) shift position, (e) change orientation, and (f) control of viewpoint.

viewed by zooming-in at maximum with the zoom-in and zoom-out functions, as can be seen in Figure A1 (d).

The viewpoint for the landscape could be controlled along the rover's path with a slider (Figure A2 (f)). The icons in Figures A2 (d) and (e) could also be used to freely control the viewpoint. 


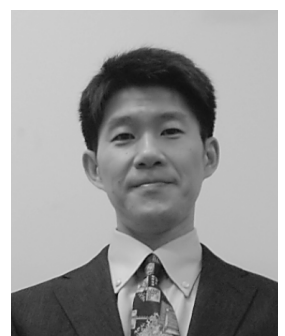

Kikuo Asai received a B.E. degree in Electric and Electronic Engineering from Meijo University, Japan and his M.E. and Ph.D. degrees in Electrical Engineering and Electronics from Nagoya University, Japan in 1993 and 1998, respectively. He joined the National Institute of Multimedia Education in 1996. He was a visiting researcher at the University of Illinois-Chicago in 2000, at the University of Alberta in 2002-2003, and at the University of Canterbury in 2009-2010. He is currently an associate professor at The Open University of Japan. He has been engaged in research and development on communication networks, multimedia systems and human computer interaction. He is a member of IEICE, IEEJ, VRSJ, and ACM.

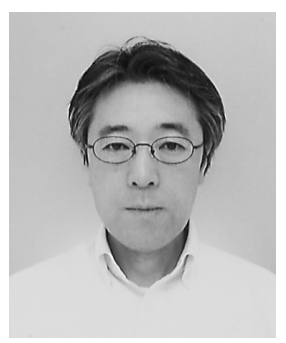

Tomotsugu Kondo is an Associate Professor of the Center of ICT and Distance Education at the Open University of Japan (OUJ). He received a B.Ed. degree from Hosei University, Japan and his M.Ed. degree in infant psychology from Joetsu University of Education, Japan in 1988. He joined the National Institute of Multimedia Education in 1995. He was a visiting researcher at the Fraunhofer IGD in Darmstadt in 2003 and the Knowledge Media Research Center (KMRC) in Tübingen in 2010. He has been engaged in research and development on mixed reality contents. He is a member of IEEE, Japan Society for Exhibition Studies and Japan Society for Educational Technology.

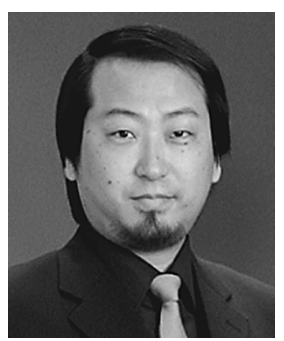

Hideaki Kobayashi received his B.S. degree in Physics from Tokyo University of Science, Japan in 1997 and served a member of the technical staff at Saitama University from 1994 to 2000. He received his M.S. degrees in Physics from Tokyo University of Science in 1999 and in Education from University of Tsukuba in 2003. He did research on educational psychology at The Graduate University for Advanced Studies. He is currently a visiting researcher in Advanced Research Center for Human Sciences at Waseda University. His research interests include multimedia learning systems, immersive virtual environments, and human-computer interfaces. He is a member of SJST, JSSE, JSET, and IEICE.

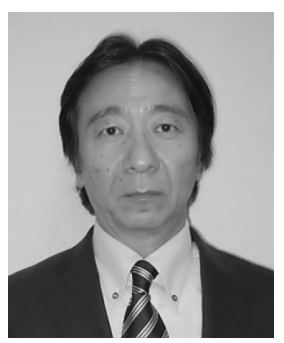

Yuji Y. Sugimoto received B. Eng., M. Eng. and Ph.D. degrees in engineering electronics from Doshisha University, Kyoto, Japan in 1973, 1976 and 1997, respectively. In 1976, he joined the Radio Research Laboratories (presently, National Institute of Information and Communications Technology (NICT)), Japan. Later, he studied the VLBI correlation processor at the Jet Propulsion Laboratory, California Institute of Technology. In 1998, he joined the National Institute of Multimedia Education. In 2005, he became a professor in the Faculty of Culture and Information Science, Doshisha University, and has been engaged in the "Cultural Human-Computer Interaction Laboratory." (CHCI Lab.) In 2007, he became a professor of the Graduate School of the Faculty of Culture and Information Science, Doshisha University. From 2010 to 2011, he studied interface systems between human and computer systems including various kinds of culture at the Electronic Visualization Laboratory (EVL), University of Illinois-Chicago as a visiting research scholar. He is a member of the Institute of Electronics, Information and Communication Engineers, Japan (IEICE), and the Virtual Reality Society of Japan (VRSJ). 